\title{
Erythrocyte aggregation: Basic aspects and clinical importance
}

\author{
Oguz K. Baskurt ${ }^{\mathrm{a}, *}$ and Herbert J. Meiselman ${ }^{\mathrm{b}}$ \\ ${ }^{a}$ Koc University School of Medicine, Istanbul, Turkey \\ ${ }^{\mathrm{b}}$ Keck School of Medicine, University of Southern California, Los Angeles, CA, USA
}

\begin{abstract}
Red blood cells (RBC) aggregate to form two- and three-dimensional structures when suspended in aqueous solutions containing large plasma proteins or polymers; this aggregation is reversible and shear dependent (i.e., dispersed at high shear and reformed at low or stasis). The extent of aggregation is the main determinant of low shear blood viscosity, thus predicting an inverse relationship between aggregation and in vivo blood flow. However, the effects of aggregation on hemodynamic mechanisms (e.g., plasma skimming, Fåhraeus Effect, microvascular hematocrit) may promote rather than impede vascular blood flow. The impact of enhanced RBC aggregation on endothelial function and hemostatic mechanisms adds further complexity, thereby requiring specific attention to the nature, extent and time course of aggregation when considering its overall influence on tissue perfusion. A detailed understanding of aggregation effects is important from a clinical point of view since it may be enhanced during a variety of pathophysiological processes, including infections, circulatory and metabolic disorders, hematological pathologies and several other disease states. Altered RBC aggregation may be an indicator of disease as well as a factor affecting the course of the clinical condition; the prognostic value of RBC aggregation indices has been demonstrated in various diseases. Currently, $\mathrm{RBC}$ aggregation is an easily and accurately measurable parameter, and therefore may be expected to have broader clinical usage in the future.
\end{abstract}

Keywords: Inflammation, aggregability, hemorheology, tissue perfusion

\section{Red blood cell aggregation}

Human red blood cells (RBC) are able to aggregate to form two- and three-dimensional structures when suspended in aqueous solutions containing large plasma proteins (e.g., fibrinogen) or polymers (e.g., $70 \mathrm{kDa}$ dextran) $[18,86,88]$. These structures form at stasis or when fluid shear forces are sufficiently low, and can be dispersed by higher shear forces; the aggregation process is reversible when shear forces are decreased or eliminated. The two-dimensional structures are formed by face-to-face contact of cells into linear arrays whose shape is similar to a stack of coins; these structures are often termed rouleau (singular) or rouleaux (plural). Figure 1 shows a representative assortment of rouleaux for normal human $\mathrm{RBC}$ in autologous plasma, where it is obvious that: 1) the number of RBC per rouleau can vary widely; 2) side-to-side or side-to-end branching can occur. Note that while the aggregates shown in Fig. 1 were formed in a thin two-dimensional geometry (i.e., between a microscope slide and cover slip), rouleaux can form three-dimensional structures in larger geometries. The formation of these larger structures is affected by factors such as available space and the level of cell-to-cell attractive forces.

\footnotetext{
${ }^{*}$ Corresponding author: Oguz K. Baskurt, Koc University School of Medicine, Istanbul, Turkey. E-mail: obaskurt@ ku.edu.tr.
} 


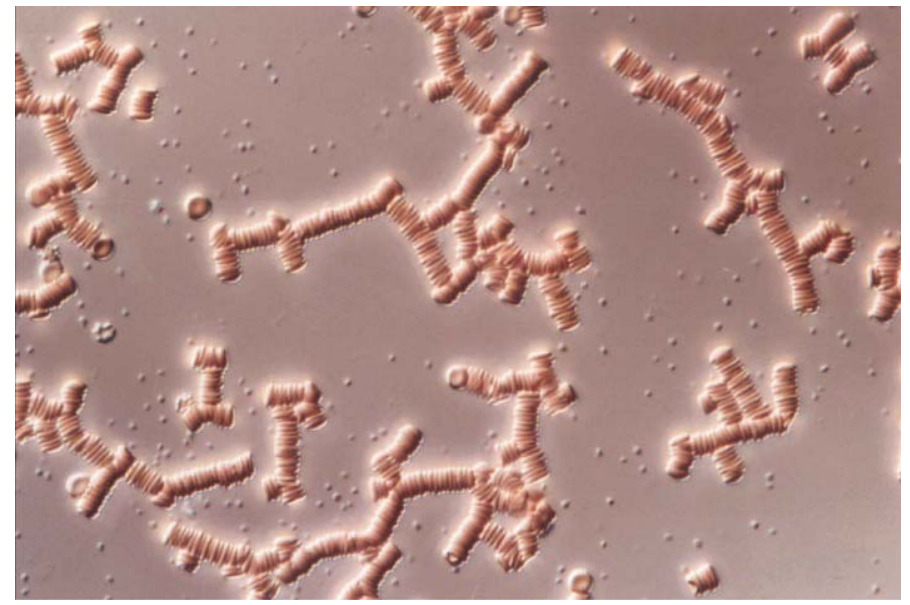

Fig. 1. Red blood cell aggregates in autologous plasma at stasis. Small round particles are blood platelets that were not removed from plasma.

$\mathrm{RBC}$ aggregation is a relatively fast process with time constants of about seconds for initial rouleau formation and somewhat longer for forming three-dimensional aggregates. Therefore, RBC aggregates may form in various parts of the circulatory system (i.e., in areas with low shear forces) and in various testing systems outside the body. The phenomenon of RBC aggregation has been known since the $18^{\text {th }}$ century and was described as "the less uniformly diffused red globules" under primitive microscopes [107], with this appearance a consequence of the separation of aggregates and plasma from each other. This separation resulted in a "dotted" appearance of the blood when observed between two flat glass surfaces and was observable even by the naked eye; the degree of this separation was accepted as an indicator of inflammatory status [57].

Robin Fåhraeus was the scientist who initially investigated in detail the relationship between RBC aggregation and the suspension stability of blood [57]. His work was instrumental in relating the aggregation process to the erythrocyte sedimentation rate (ESR) which was previously described by Biernacki [32]. Since the early $20^{\text {th }}$ century, ESR has been one of the most widely used clinical laboratory tests as a non-specific indicator of inflammation and the acute phase reaction [18].

\section{Factors affecting red blood cell aggregation}

The concentration of high-molecular weight, fibrous biomolecules in the suspending medium are important determinants of aggregation. The protein fibrinogen is the major plasma component promoting RBC aggregation in blood, with an almost linear relationship between aggregate size and plasma fibrinogen concentration [107]. Relations between aggregation and both the concentration and molecular mass of neutral polymers (e.g., dextran) have been studied in some detail [9, 93, 97]. Surface properties of RBC can also significantly affect the aggregation process [108]: when washed and re-suspended in a defined polymer or protein solution, differences between healthy donors and between young and old RBC have been demonstrated $[86,88]$. It has been shown that reducing the surface charge density of RBC by enzymatic treatments increases their aggregation in standard aggregating media [18, 47]. Interestingly, a 
potential artifact that can occur when measuring $\mathrm{RBC}$ with reduced surface charge has been reported: if the resulting aggregation is extremely strong, the aggregates may not be fully dispersed by shear forces (see Section 5 below) and hence some instruments indicate reduced aggregation [36]. RBC deformability is an important cellular property for aggregation [13] since cells must change their shape to form parallel membrane surfaces in rouleaux (Fig. 1). The properties of the glycocalyx on the exterior of the RBC membrane are also important determinants of aggregation behavior [88, 95].

\section{Aggregation versus aggregability}

These two terms are often used interchangeably yet have quite different meanings [12]. RBC Aggregation is the reversible process of RBC forming linear and three-dimensional aggregates. Various indices of aggregation for blood or RBC suspensions can be measured using several techniques (see Section 5); such indices are specific to the cell suspension being studied, with their magnitude affected by the properties of the cells and the suspending medium. RBC Aggregability reflects the intrinsic tendency of RBC to form aggregates and is thus a cellular property that can be affected by several physiochemical factors. The determination of RBC aggregability requires a comparison of cell populations in the same suspending medium [9]: cells exhibiting greater aggregation in the same medium have enhanced aggregability. Note that merely measuring aggregation, even in a defined suspending medium, does not by itself provide a basis for judging aggregability: comparisons among different RBC populations using the same suspending medium are essential $[10,18]$.

\section{Mechanisms for RBC aggregation}

At present, the mechanisms involved in RBC aggregation have not been fully defined. Currently, there are two co-existing but almost mutually exclusive models for aggregation: the bridging model and the depletion model [18]. In the bridging model, RBC aggregation is proposed to occur due to large macromolecules, such as plasma proteins, adsorbing on to adjacent cells [39]. The bridging model proposes that RBC aggregation occurs when bridging forces due to the adsorption of macromolecules onto adjacent cell surfaces exceed disaggregating forces due to electrostatic repulsion, membrane strain and mechanical shearing [47-49]. In contrast, the depletion model proposes quite the opposite. In this model, RBC aggregation occurs because of a lower localized protein or polymer concentration near the cell surface compared to the suspending medium (i.e., relative depletion near the cell surface). When two $\mathrm{RBC}$ are in close proximity, this exclusion of macromolecules near the cell surface leads to an osmotic gradient, depletion interaction, and attractive forces [28, 29]. As with the bridging model, aggregation occurs when the cell-cell attractive forces exceed disaggregating forces due to electrostatic repulsion, membrane strain and mechanical shearing. The depletion concept was first introduced by Asakura and Oosawa [7] more than half a century ago; a depletion layer develops near the surface in contact with a polymer solution if the entropy of the polymer is not balanced by adsorption energy [94, 95].

While it is not yet possible to unequivalently decide between these two mechanisms, several recent studies favoring the depletion model have been published: 1) attractive forces due to depletion are of appropriate magnitude and agree with literature values [93];2) the large differences in aggregation and aggregability (see Section 3) between young and old RBC can be predicted based on the magnitude of attractive forces [96]; 3) depletion forces are sufficient to promote adhesion of RBC to albumin-coated surfaces [92]; 4) the effects of dextran molecular mass on RBC aggregation can also be predicted based 
on the depletion model [97]. Experimental evidence based on the attachment of a polymer to the RBC surface does not support the bridging model [6].

\section{Measurement of red blood cell aggregation}

$\mathrm{RBC}$ aggregation is a measurable property of blood and $\mathrm{RBC}$ suspensions that has a characteristic time course during which the suspension approaches a steady state; parameters indicating the extent and rate of the aggregate formation can be obtained by analyzing this time course. There are various approaches to quantifying RBC aggregation including erythrocyte sedimentation rate (ESR) [109], centrifugation methods (e.g., zeta sedimentation ratio) [41], microscopic methods including computerized image analysis techniques [45, 48, 111], low shear viscometry [38, 42], ultrasound imaging [52], monitoring electrical properties [22] and analysis of light transmission or reflection of RBC suspensions [65, 69]. The reader is referred to the cited references and recent publications in the area for detailed description of these methods $[18,66]$; techniques based on the optical properties of RBC suspensions (i.e., light transmission or reflection) are briefly described below.

\subsection{Syllectometry for measuring red blood cell aggregation}

Zillstra studied the optical properties of RBC suspensions in the 1950's and recognized that the time course of back-scattered light intensity from RBC suspensions reflects the time course of RBC aggregation [131]. He named this method syllectometry and termed the recorded light intensity time course a syllectogram [131]. This approach has since been utilized by many investigators and extended to include the analysis of light transmission [59, 65, 69]. A number of aggregometers have been built based on light transmission or backscattering, with some being commercialized [24].

The light transmission or backscattering through or from a suspension of particles is a function of the number of particles, their sizes and optical properties. Aggregation of RBC results in decrease of the number of particles in suspension and an increase of particle size. This process results in increased light transmission or decreased backscattering. Monitoring of transmitted/reflected light intensity during aggregation process following a complete disaggregation provides a time course which can be mathematically analyzed to derive aggregation indexes reflecting both the aggregate size (i.e., an average number of $\mathrm{RBC}$ per aggregate) and the time course of $\mathrm{RBC}$ aggregation (e.g., aggregation half time and time constants).

Although most devices developed for measuring RBC aggregation utilize similar approaches for recording and analyzing light intensity signals, the shearing system used for complete disaggregation as the starting point for recording the signal varies significantly between devices. Co-axial cylindrical viscometers (Couette) [65], cone-plate [69] or plate-plate [17] rotational shearing systems, parallel-plate flow chambers [114], mechanical stirring mechanisms [115] and microfluidic systems vibrating blood samples in disposable tubes [23] have been used for disaggregation. Light intensity signals, either transmitted or backscattered, have typical time courses [21, 116]: following the disaggregation process and after an abrupt cessation of shear, an increase of transmitted light or a decrease of reflected light occurs with a fast time course followed by a second phase of slower change, the entire process completed in about one hundred seconds. A mathematical analysis (i.e., a double-exponential curve fit) yields two time constants, $t_{\text {fast }}$ and $t_{\text {slow }}$, that together describe the time course of $\mathrm{RBC}$ aggregation $[18,65]$. Additionally, the integration of the syllectogram curve within selected times provides an index of the 
extent of RBC aggregation and is utilized as an aggregation index by a number of aggregometers [17, $65,69,115]$. RBC aggregation measurement based on syllectometry is a fast, accurate and reliable approach [10] and has been utilized in laboratory devices developed as alternatives to the conventional methods of measuring ESR [23, 67, 102]. RBC aggregation indices obtained by syllectometry have been proven to be useful in monitoring the acute phase response and inflammatory processes [30, $60,79,84]$, and offer the potential to be used as point-of-care devices for monitoring inflammation [23].

\section{Red blood cell aggregation and tissue-organ perfusion}

Ex vivo investigations of the flow properties of blood have clearly shown that $\mathrm{RBC}$ aggregation is a major determinant of low shear blood viscosity: at constant hematocrit, enhanced aggregation increases low shear viscosity and the degree of non-Newtonian flow behavior [53, 55]. Direct extrapolation of these findings to in vivo blood flow has led to the classical view regarding the hemodynamic consequences of $\mathrm{RBC}$ aggregation that predicts a negative correlation between the extent of RBC aggregation and tissue perfusion $[8,16]$. This correlation has been considered, and even demonstrated, to be especially relevant in areas of the circulatory system with relatively low effective shear forces (e.g., venous vessels) [15, 16]. This influence of RBC aggregation on venous flow resistance has been suggested to play a role in capillary flow dynamics and in fluid exchange: the fluid exchange effect arises due to the influence of aggregation on post-capillary resistance, the pre- to post-capillary resistance ratio and hence on mean capillary blood pressure [43].

However, further detailed analyses of the in vivo consequences of enhanced RBC aggregation indicate a more complex situation that leads to an alternative view to those predictions based solely on ex vivo blood viscosity data $[8,15]$. This alternative view includes the influence of RBC aggregation on microcirculatory hemodynamics, with findings that suggest either improved or worsened blood flow. A complete discussion of the hemodynamic consequences of RBC aggregation is beyond of the scope of this review; a brief summary is presented below and in Figure 2.

It has been well documented that RBC aggregation promotes the axial accumulation of RBC in tube flow and in blood vessels [34, 63, 70, 99]. Cokelet and Goldsmith demonstrated that this enhanced axial accumulation of $\mathrm{RBC}$, which was induced by experimentally-increased $\mathrm{RBC}$ aggregation, results in reduced flow resistance [54]. This result can be explained by the altered composition of the blood in the marginal layers of the vessel. That is, accumulation of RBC in the central flow zone reduces hematocrit and hence viscosity near the vessel wall. Another important consequence of RBC axial accumulation is the reduced hematocrit in micro vessels $[25,112]$. This reduction is directly related to the perfusion of side branches of blood vessels from the lower-hematocrit marginal region and not from the entire vessel; this mechanism is known as plasma skimming [103, 104].

Axial accumulation is also the main mechanism underlying the Fåhraeus Effect (i.e., reduction of tube or vessel hematocrit with reducing tube or vessel diameter) [57]. The velocity profile in tube flow can be predicted from the Navier-Stokes equation and can be demonstrated experimentally: fluid lamina in the central flow zone have higher velocities compared to those in the marginal zone [33, 44]. This hydrodynamic situation, together with the above-mentioned axial accumulation of RBC in the fastermoving axial region, results in a lower average hematocrit in a blood vessel compared to that of the blood entering or discharged from that vessel [62]. The extent of the Fåhraeus Effect depends on the vessel size and can be neglected for diameters greater than about $500 \mu \mathrm{m}$. 


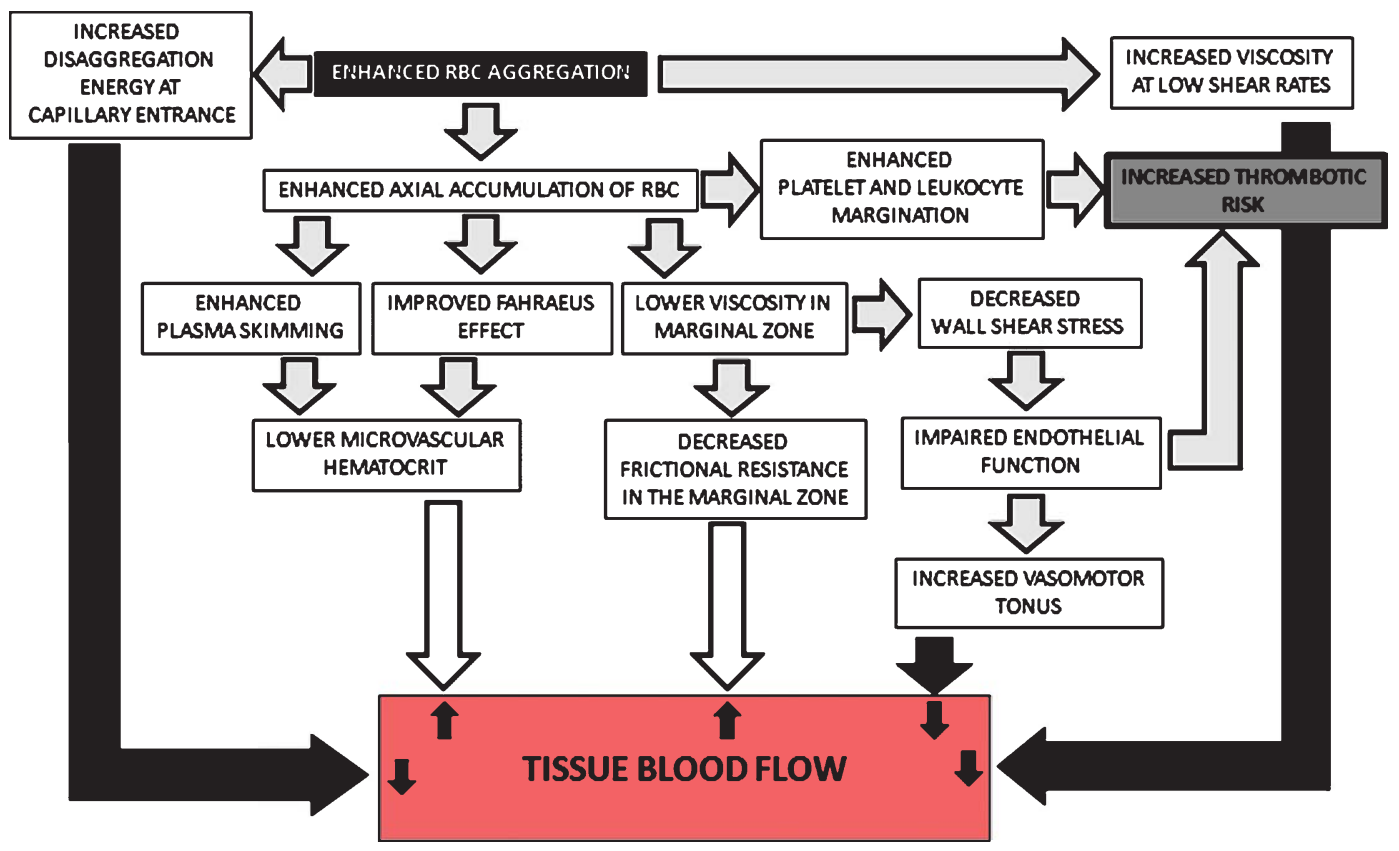

Fig. 2. Effect of enhanced red blood cell aggregation on tissue blood flow. Note that there are two types of final effects: increasing (white arrows) or decreasing (black arrows) tissue blood flow as a result of various intermediate mechanisms. Enhanced red blood cell aggregation may also increase thrombosis risk. See the text for detailed explanation.

Plasma skimming and the Fåhraeus Effect both contribute to the significantly lower microvascular hematocrit compared to arterial and/or venous hematocrit. Hematocrit values as low as $20 \%$ of venous hematocrit have been reported [72, 82]; this reduced micro-vessel hematocrit also contributes to a lower than expected hemodynamic resistance when there is enhanced RBC aggregation [100].

The influence of $\mathrm{RBC}$ aggregation on measured microvascular hematocrit $[26,100,129]$ strongly suggests that RBC aggregates exist on the arterial side of the circulatory system $[8,15]$. It then follows from this suggestion that these "arterial" RBC aggregates must be dispersed into individual RBC in order for cells to pass through the terminal microvasculature (i.e., capillaries). This disaggregation process has an energy cost and hence tends to increase the flow resistance of the microcirculation, an effect of aggregation that contrasts with the beneficial influence of RBC aggregation on blood flow [8, 15]. In overview, the net effect of a change in RBC aggregation on microcirculatory blood flow is determined by the balance between the abovementioned opposing influences (i.e., axial accumulation plus reduced microvascular hematocrit versus the energy costs required for dispersing aggregates, see Fig. 2).

Recent studies dealing with the effects of enhanced RBC aggregation on endothelial function indicate that the vascular geometry component of hemodynamic resistance can also be involved in this complex relationship [26, 130]. These studies were prompted by observations that RBC aggregation can reduce frictional resistance via lowering hematocrit and hence viscosity in the near-wall region, thereby resulting in lower wall shear stress [54]. This suggestion stimulated research into possible modifications of endothelial cell function in response to altered RBC aggregation.

Using an in vivo model of chronically enhanced RBC aggregation, it has been shown that nitric oxide (NO) synthesis mechanisms in skeletal muscle vasculature are down-regulated and accompanied by 
blunted NO-related vasomotor mechanisms [26]. Further studies using in vitro systems have supported these findings and have been extended to include the response of NO synthase expression that was dependent on the method by which RBC aggregation was altered [130]. RBC aggregation that was elevated by adding large polymers to alter plasma composition, and therefore increasing plasma viscosity, was less effective compared to enhanced aggregation achieved by enhancing RBC aggregability without altering plasma composition [130]. These findings can be interpreted as indicating the importance of considering the mechanism by which aggregation is altered in addition to considering its extent and kinetics. Enhanced RBC aggregation due to increased concentrations of acute phase reactants (e.g., fibrinogen), as in case of inflammatory disorders, may not be as effective as enhanced aggregation due to increased RBC aggregability as seen in pathophysiological conditions such as sepsis, diabetes and hemoglobinopathies [19, 46, 50], in affecting endothelial function.

The disturbance of endothelial function due to enhanced RBC aggregation, as evidenced by downregulation of NO-related mechanisms [26, 130], may also increase thrombotic risk [11]; processes leading to this increased risk are shown schematically in Fig. 2. NO is a well-established anti-thrombotic agent and helps maintain the non-thrombogenic status of vascular endothelium and platelets [83]. Further, enhanced aggregation and the induced central compaction of RBC favors the migration of platelets to the marginal flow zone $[61,91]$. Note that enhanced RBC aggregation can have two potential and opposing effects on shear forces near the vessel wall: 1) Aggregation promotes RBC axial accumulation, thereby reducing local hematocrit and viscosity near the wall. Since shear stress is proportional to shear rate times viscosity, stress levels are reduced; 2) Aggregation also changes the velocity profile within a vessel making it more blunted than parabolic. Thus, the velocity profile near the wall is steeper, local shear rate is increased, and stress levels are elevated. Both of these effects modulate shear forces in the marginal zone where platelets are accumulated [34] and hence modulate the possibility of platelet activation [11]. The relative importance of these two effects at any moment will depend on the intensity of RBC aggregation and the flow conditions in a vessel (e.g., volumetric flow rate, vessel size).

\section{Alterations in red blood cell aggregation: Brief review of clinical findings}

$\mathrm{RBC}$ aggregation has been reported to be altered in a number of clinical conditions. A complete survey of this area is beyond the scope of this paper; many examples can be found in the journals in the area (e.g., Clinical Hemorheology and Microcirculation, IOS Press) and are summarized in recent publications [e.g., 16, 18]. Inflammatory conditions and related acute phase reactions constitute an important aspect of clinical conditions associated with enhanced RBC aggregation $[18,106]$. Increased plasma concentrations of acute phase reactants (e.g., fibrinogen) are mainly responsible for the enhanced RBC aggregation in response to inflammation [107].

\subsection{Infections}

The relationship between RBC aggregation parameters and inflammatory markers in a variety of infectious diseases is well established [3, 30, 60, 105, 121]. However, it has also been demonstrated that enhanced aggregation in cases of infection cannot solely be explained by increased levels of acute phase reactants; cellular properties of RBC are also be altered in severe infectious diseases [19, 30]. Ben Ami, et al. estimated that about $65 \%$ of the enhancement in RBC aggregation can be explained by alterations in plasma factors, with the remaining 35\% reported to reflect changes in cellular properties in patients 
with serious infectious diseases such as pneumonia, urinary infections and septicemia [30]. Enhanced RBC aggregation caused by alterations of both plasmatic and cellular factors has also been reported in severe infections (e.g., sepsis) by other groups $[5,31,71]$. The exact nature of the alterations in cellular properties has not been described in detail, but may include the influence of activated neutrophils and free radical damage to $\mathrm{RBC}[14,20]$. A simple test based on $\mathrm{RBC}$ aggregation has been proposed as an approach to differentiate between acute bacterial and viral infections; significantly enhanced aggregation detected with this "slide test" indicated the existence of bacterial infections in pediatric patients, while patients with viral infections had lower RBC aggregation [60].

\subsection{Cardiovascular diseases}

Acute circulatory problems of various organs have been reported to be characterized by increased RBC aggregation. These conditions include myocardial ischemia and infarction [30,68, 78, 133], cerebral ischemia and infarction [37, 120] and peripheral vascular diseases [73, 75]. The enhancement of RBC aggregation is more prominent in cases of infarction compared to ischemia [30] and during the acute phase of the pathophysiological process [119]. Enhanced RBC aggregation has also been reported in cases of milder clinical manifestations such as stable angina and slow coronary syndrome $[56,77,78]$, and it has been argued that the enhanced RBC aggregation in such disorders might contribute to the pathophysiology [77].

There is a large collection of clinical studies reporting enhanced RBC aggregation in hypertension $[51,58,76,89]$, with the severity and type of hypertension indicated as the determinants of altered RBC aggregation $[1,80]$. Plasmatic factors of aggregation have been frequently reported to be increased in hypertensive patients $[35,81,125]$, while altered cellular properties have been observed in hypertensive animal models [64]. Hypertension is a typical example of a possible two-way interaction between hemorheological parameters and circulatory disorders [35, 87]: hemorheological alterations, in particular RBC aggregation, may be considered the cause or the result of the circulatory disorder (e.g., hypertension). It can easily be argued that microvascular damage due to hypertension may induce an acute phase reaction and enhance aggregation [101]. Enhanced RBC aggregation may have an influence on peripheral vascular resistance either directly or indirectly via altered endothelial function [26]; abnormal endothelial behavior may further increase blood pressure, thereby generating a vicious cycle [87].

It is interesting to note that a prognostic value has been attributed to RBC aggregation in patients with unstable angina $[98,110]$. Neumann, et al., reported a significant difference in the event-free survival rates of patients with unstable angina who had high or low RBC aggregation indices during their admission to the hospital [98].

\subsection{Metabolic disorders}

Hemorheological alterations in diabetes have been reported by various groups and these disturbances of blood rheological behavior include enhanced RBC aggregation [27, 132]. Significant correlations were reported between RBC aggregation parameters and hemoglobin A1c levels as an indicator of glycemic control [132]. A longitudinal study indicated significant decreases of RBC aggregation in response to improved diabetic control [50]. It has been reported that RBC aggregation increases are more prominent in patients with vascular complications [85, 90, 127]. This enhancement of RBC aggregation is partly related to increased fibrinogen concentrations in plasma, but changes of RBC properties have also been reported to contribute to RBC aggregation in diabetic patients [50]. While alterations of plasmatic and 
cellular factors contributing to altered RBC aggregation may result from vascular disorders in diabetes in certain patient groups, a significant correlation has been demonstrated between insulin resistance and RBC aggregation in subjects without established diabetes and vascular complications [40].

Enhanced RBC aggregation has also been reported in patients with metabolic syndrome [4, 122, 123] and correlations have been demonstrated between the extent of aggregation and the number of components of the syndrome [122]. This association has been suggested to reflect the inflammatory process that is present in this syndrome. Vaya, et al. reported higher aggregation indices in morbidly obese patients [124]; weight loss in obese patients tends to normalize RBC aggregation [117].

\subsection{Hematological diseases}

RBC aggregation is altered in patients with hemoglobinopathies. Enhanced RBC aggregation was reported in $\beta$-thalassemia major patients [46], which can be explained by the well-known oxidative damage in such RBC [113]. Waltz, et al. reported a lower RBC aggregation index but a higher disaggregation shear rate threshold in patients with sickle-cell anemia, compared to controls [128]. Obviously, the altered morphology and deformability of sickle RBC may explain the decreased aggregation [2], while the enhanced aggregate strength needs further evaluation.

Specific alterations in plasma proteins should also be considered among the causes of enhanced aggregation. Greatly enhanced RBC aggregation has been reported in cases of plasma cell dyscrasias with high plasma immunoglobulin concentrations [74]. Chronic inflammatory disorders are usually associated with high RBC aggregation; rheumatoid arthritis is a classic example of enhanced RBC aggregation due to chronic inflammation. Other autoimmune, inflammatory diseases such as systemic lupus erytematosus (SLE) have been reported to manifest high RBC aggregation [118, 126]; Spengler, et al. reported positive correlations of RBC aggregation with fibrinogen and with immunoglobulins in patients with SLE [118].

\section{Conclusion}

$\mathrm{RBC}$ aggregation is a physiological property and an important determinant of in vivo blood flow dynamics. Significant alterations under various pathophysiological conditions add clinical importance to this phenomenon, thereby raising several questions: 1) Is RBC aggregation "good" or "bad" for tissue perfusion? 2) Is there an optimum level of RBC aggregation that should be maintained under physiological conditions? 3) Is enhanced RBC aggregation a challenge for maintaining physiological status and should it be corrected by therapeutic measures or is it only an indicator of inflammatory processes? These questions remain to be answered despite the numerous experimental and clinical studies conducted during the past several decades.

\section{References}

[1] R.S. Ajmani, Hypertension and hemorheology, Clin Hemorheol Microcirc 17 (1997), 397-420.

[2] T. Alexy, S. Sangkatumvong, P. Connes, E. Pais, J. Tripette, J.C. Barthelemy, T.C. Fisher, H.J. Meiselman, M.C. Khoo and T.D. Coates, Sickle cell disease: Selected aspects of pathophysiology, Clin Hemorheol Microcirc 44 (2010), $155-166$. 
[3] B. Almog, R. Gamzu, R. Almog, J.B. Lessing, I. Shapira, S. Berliner, D. Pauzner, S. Maslovitz and I. Levin, Enhanced erythrocyte aggregation in clinically diagnosed pelvic inflammatory disease, Sexually Transmitted Diseases 32 (2005), 484-486.

[4] I. Aloulou, E. Varlet-Marie, J. Mercier and J.F. Brun, Hemorheologic effects of low intensity endurance training in sedentary patients suffering from the metabolic syndrome, Clin Hemorheol Microcirc 35 (2006), 333-339.

[5] E. Alt, B.R. Mann-Vesti, C. Madl, G. Funk and R. Koppensteiner, Platelet aggregation and blood rheology in severe sepsis/septic shock, Clin Hemorheol Microcirc 30 (2004), 107-115.

[6] J.K. Armstrong, H.J. Meiselman and T.C. Fisher, Evidence against macromolecular bridging as the mechanism of red blood cell aggregation induced by nonionic polymers, Biorheology 36 (1999), 433-437.

[7] T. Asakura and F. Oosawa, On interaction between two bodies immersed in a solution of macromolecules, J Chem Physics 22 (1954), 1255-1256.

[8] O.K. Baskurt, In vivo correlates of altered blood rheology, Biorheology 45 (2008), 629-638.

[9] O.K. Baskurt, M. Bor-Kucukatay, O. Yalcin, H.J. Meiselman and J.K. Armstrong, Standard aggregating media to test the "aggregability" of rat red blood cells, Clin Hemorheol Microcirc 22 (2000), 161-166.

[10] O.K. Baskurt, M. Boynard, G.R. Cokelet, P. Connes, B.M. Cooke, S. Forconi, F. Liao, M.R. Hardeman, F. Jung, H.J. Meiselman, G.B. Nash, N. Nemeth, B. Neu, B. Sandhagen, S. Shin, G.B. Thurston and J.L. Wautier, New guidelines for hemorheological laboratory techniques, Clin Hemorheol Microcirc 42 (2009), 75-97.

[11] O.K. Baskurt and H.J. Meiselman, Iatrogenic hyperviscosity and thrombosis, Semin Thromb Hemost (2012), In press.

[12] O.K. Baskurt and H.J. Meiselman, Red blood cell aggregability, Clin Hemorheol Microcirc 43 (2009), 353-354.

[13] O.K. Baskurt and H.J. Meiselman, Cellular determinants of low-shear blood viscosity, Biorheology 34 (1997), 235-247.

[14] O.K. Baskurt and H.J. Meiselman, Activated polymorphonuclear leukocytes affect red blood cell aggregability, J Leukoc Biol 63 (1998), 89-93.

[15] O.K. Baskurt and H.J. Meiselman, Hemodynamic effects of red blood cell aggregation, Ind J Exp Biol 45 (2007), $25-31$.

[16] O.K. Baskurt and H.J. Meiselman, In vivo hemorheology, in: O.K. Baskurt, M.R. Hardeman, M.W. Rampling and H.J. Meiselman, eds, Handbook of Hemorheology and Hemodynamics, IOS Press, Amsterdam, Berlin, Oxford, Tokyo, Washington D.C., 2007, pp. 322-338.

[17] O.K. Baskurt, H.J. Meiselman and E. Kayar, Measurement of red blood cell aggregation in a "plate-plate" shearing system by analysis of light transmission, Clin Hemorheol Microcirc 19 (1998), 307-314.

[18] O.K. Baskurt, B. Neu and H.J. Meiselman, Red Blood Cell Aggregation, Boca Raton, Florida, CRC Press, 2012.

[19] O.K. Baskurt, A. Temiz and H.J. Meiselman, Red blood cell aggregation in experimental sepsis, J Lab Clin Med 130 (1997), 183-190.

[20] O.K. Baskurt, A. Temiz and H.J. Meiselman, Effect of superoxide anions on red blood cell rheologic properties, Free Radic Biol Med 24 (1998), 102-110.

[21] O.K. Baskurt, M. Uyuklu, M.R. Hardeman and H.J. Meiselman, Photometric measurements of red blood cell aggregation: Light transmission versus light reflectance, J Biomed Optics 14 (2009), 54044.

[22] O.K. Baskurt, M. Uyuklu and H.J. Meiselman, Time course of electrical impedance during red blood cell aggregation in a glass tube: Comparison with light transmittance, IEEE Trans Biomed Eng 57 (2010), 969-978.

[23] O.K. Baskurt, M. Uyuklu, S. Ozdem and H.J. Meiselman, Measurement of red blood cell aggregation in disposable capillary tubes: Correlation with erythrocyte sedimentation rate, Clin Hemorheol Microcirc 47 (2011), 295-305.

[24] O.K. Baskurt, M. Uyuklu, P. Ulker, M. Cengiz, N. Nemeth, T. Alexy, S. Shin, M.R. Hardeman and H.J. Meiselman, Comparison of three instruments for measuring red blood cell aggregation, Clin Hemorheol Microcirc 43 (2009), $283-298$.

[25] O.K. Baskurt, O. Yalcin, F. Gungor and H.J. Meiselman, Hemorheological parameters as determinants of myocardial tissue hematocrit values, Clin Hemorheol Microcirc 35 (2006), 45-50.

[26] O.K. Baskurt, O. Yalcin, S. Ozdem, J.K. Armstrong and H.J. Meiselman, Modulation of endothelial nitric oxide synthase expression by red blood cell aggregation, Am J Physiol 286 (2004), H222-H229.

[27] R.M. Bauersachs, S.J. Shaw, A. Zeidler and H.J. Meiselman, Red blood cell aggregation and blood viscoelasticity in poorly controlled type 2 diabetes mellitus, Clin Hemorheol 9 (1989), 935-952.

[28] H. Baumler, E. Donath, A. Krabi, W. Knippel, A. Budde and H. Kiesewetter, Electrophoresis of human red blood cells and platelets. Evidence for depletion of dextran, Biorheology 33 (1996), 333-351.

[29] H. Baumler, B. Neu, R. Mitlohner, R. Georgieva, H.J. Meiselman and H. Kiesewetter, Electrophoretic and aggregation behavior of bovine, horse and human red blood cells in plasma and in polymer solutions, Biorheology 38 (2001), 39-51. 
[30] R. Ben Ami, G. Barshtein, D. Zeltser, Y. Goldberg, I. Shapira, A. Roth, G. Keren, H. Miller, V. Prochorov, A. Eldor, S. Berliner and S. Yedgar, Parameters of red blood cell aggregation as correlates of the inflammatory state, Am J Physiol Heart Circ Physiol 280 (2001), H1982-H1988.

[31] A.S. Berliner, I. Shapira, O. Rogowski, N. Sadees, R. Rotstein, R. Fusman, D. Avitzour, S. Cohen, N. Arber and D. Zeltser, Combined leukocyte and erythrocyte aggregation in the peripheral venous blood during sepsis. An indication of commonly shared adhesive protein(s), Int J Clin Lab Res 30 (2000), 27-31.

[32] E. Biernacki, Samoistna sedymentacja krwi jako naukowa, praktyczno-kliniczna metoda badania, Gazeta Lekarska 17 (1897), 962-996.

[33] J.J. Bishop, P.R. Nance, A.S. Popel, M. Intaglietta and P.C. Johnson, Effect of erythrocyte aggregation on velocity profiles in venules, Am J Physiol Heart Circ Physiol 280 (2001), H222-H236.

[34] J.J. Bishop, A.S. Popel, M. Intaglietta and P.C. Johnson, Effects of erythrocyte aggregation and venous network geometry on red blood cell axial migration, Am J Physiol Heart Circ Physiol 281 (2001), H939-H950.

[35] L. Bogar, Hemorheology and hypertension: Not "chicken or egg" but two chickens from similar eggs, Clin Hemorheol Microcirc 26 (2002), 81-83.

[36] T. Bohler and O. Linderkamp, Effect of neuraminidase and trypsin on surface charge and aggregation of red blood cells, Clin Hemorheol 13 (1993), 775-778.

[37] N. Bolokadze, I. Lobjanidze, N. Momtselidze, R. Shakarishvili and G. Mchedlishvili, Comparison of erythrocyte aggregability changes during ischemic and hemorrhagic stroke, Clin Hemorheol Microcirc 35 (2006), 265-267.

[38] D.E. Brooks, J.W. Goodwin and G.V.F. Seaman, Rheology of erythrocyte suspensions: Electrostatic factors in the dextranmediated aggregation of erythrocytes, Biorheology 11 (1974), 69-76.

[39] D.E. Brooks, R.G. Greig and J. Janzen, Mechanisms of erythrocyte aggregation, in: G.R. Cokelet, H.J. Meiselman and D.E. Brooks, eds, Erythrocyte mechanics and blood flow, A.R. Liss, New York, 1980, pp. 119-140.

[40] J.F. Brun, E. Varlet-Marie and E. Raynaud de Mauverger, Relationships between insulin sensitivity measured with the oral minimal model and blood rheology, Clin Hemorheol Microcirc 51 (2012), 29-34.

[41] B.S. Bull and J.D. Brailsford, The zeta sedimentation rate, Blood 40 (1972), 550-557.

[42] B.S. Bull, S. Chien, J. Dormandy, H. Kiesewetter, S.M. Lewis, G.D.O. Lowe, H.J. Meiselman, L.V. McIntire, M.W. Rampling, S. Shohet, J.F. Stoltz, J. Stuart, P. Teitel and J.T. Whicher, Guidelines on selection of laboratory tests for monitoring the acute phase response, J Clin Pathol 41 (1989), 1203-1212.

[43] M. Cabel, H.J. Meiselman, A.S. Popel and P.C. Johnson, Contribution of red blood cell aggregation to venous vascular resistance in skeletal muscle, Am J Physiol 272 (1997), H1020-H1032.

[44] G.P. Chatzimavroudis, Blood flow dynamics, in: J. Saleh, ed., Fluid flow handbook, McGraw-Hill, New York, 2002, pp. 26.1-26.26.

[45] S. Chen, G. Barshtein, B. Gavish, Y. Mahler and S. Yedgar, Monitoring of red blood cell aggregability in a flow-chamber by computerized image analysis, Clin Hemorheol 14 (1994), 497-508.

[46] S. Chen, A. Eldor, G. Barshtein, S. Zhang, A. Goldfarb, E. Rachmilewitz and S. Yedgar, Enhanced aggregability of red blood cells of beta-thalassemia major patients, Am J Physiol Heart Circ Physiol 270 (1996), H1951-H1956.

[47] S. Chien, Biophysical behavior of red cells in suspensions, in: D.M. Surgenor, ed., The Red Blood Cell, Academic Press, New York, 1975, pp. 1031-1133.

[48] S. Chien and K.M. Jan, Ultrastructural basis of the mechanism of rouleaux formation, Microvasc Res 5 (1973), $155-166$.

[49] S. Chien and L.A. Sung, Physicochemical basis and clinical implications of red cell aggregation, Clin Hemorheol 7 (1987), 71-91.

[50] B. Chong-Martinez, T.A. Buchanan, R.B. Wenby and H.J. Meiselman, Decreased red blood cell aggregation subsequent to improved glycaemic control in Type 2 diabetes mellitus, Diabetic Medicine 20 (2003), 301-306.

[51] G. Cicco and Pirrelli, Red blood cell (RBC) deformability, RBC aggregability and tissue oxygenation in hypertension, Clin Hemorheol Microcirc 21 (1999), 169-177.

[52] G. Cloutier, Characterization of erythrocyte aggregation with ultrasound, Biorheology 36 (1999), 443-446.

[53] G.R. Cokelet, Hemorheology and hemodynamics, Morgan \& Claypool Life Sciences, 2011.

[54] G.R. Cokelet and H.L. Goldsmith, Decreased hydrodynamic resistance in the two-phase flow of blood through small vertical tubes at low flow rates, Circ Res 68 (1991), 1-17.

[55] G.R. Cokelet and H.J. Meiselman, Macro- and micro-rheological properties of blood, in: O.K. Baskurt, M.R. Hardeman, M.W. Rampling and H.J. Meiselman, eds, Handbook of Hemorheology and Hemodynamics, IOS Press, Amsterdam, Berlin, Oxford, Tokyo, Washington, DC, 2007, pp. 45-71. 
[56] K. Ergun-Cagli, E. Ileri-Gurel, O. Ozeke, N. Seringec, A. Yalcinkaya, S. Kocabeyoglu, F.N. Basar, N. Sen, K. Cagli and N. Dikmenoglu, Blood viscosity changes in slow coronary flow patients, Clin Hemorheol Microcirc 47 (2011), 27-35.

[57] R. Fahraeus, The suspension stability of the blood, Physiol Rev 9 (1929), 241-274.

[58] P. Foresto, M. D’Arrigo, F. Filippin, R. Gallo, L. Barberena, L. Racca, J. Valverde and R.J. Rasia, Hemorheological alterations in hypertensive patients, Medicina-Buenos Aires 65 (2005), 121-125.

[59] A. Gaspar-Rosas and G.B. Thurston, Erythrocyte aggregate rheology by transmitted and reflected light, Biorheology 25 (1988), 471-487.

[60] Y. Goldin, T. Tulshinski, Y. Arbel, O. Rogowski, R. Ben Ami, J. Serov, P. Halperin, I. Shapira and S. Berliner, Rheological consequences of acute infections: The rheodifference between viral and bacterial infections, Clin Hemorheol Microcirc 36 (2007), 111-119.

[61] H.L. Goldsmith, D.N. Bell, S. Spain and F.A. McIntosh, Effect of red blood cells and their aggregates on platelets and white cells in flowing blood, Biorheology 36 (1999), 461-468.

[62] H.L. Goldsmith, G.R. Cokelet and P. Gaehtgens, Robin Fahraeus: Evolution of his concepts in cardiovascular physiology, Am J Physiol 257 (1989), H1005-H1015.

[63] H.L. Goldsmith and S.G. Mason, Axial migration of particles in Poiseuille flow, Nature 190 (1961), 10951096.

[64] G. Hacioglu, O. Yalcin, M. Bor-Kucukatay, G. Ozkaya and O.K. Baskurt, Red blood cell rheological properties in various rat hypertension models, Clin Hemorheol Microcirc 26 (2002), 27-32.

[65] M.R. Hardeman, J.G.G. Dobbe and C. Ince, The laser-assisted optical rotational cell analyzer (LORCA) as red blood cell aggregometer, Clin Hemorheol Microcirc 25 (2001), 1-11.

[66] M.R. Hardeman, P.T. Goedhart and S. Shin, Methods in hemorheology, in: O.K. Baskurt, M.R. Hardeman, M.W. Rampling and H.J. Meiselman, eds, Handbook Hemorheology and Hemodynamics, IOS Press, Amsterdam, Berlin, Oxford, Tokyo, Washington DC, 2007, pp. 242-266.

[67] M.R. Hardeman, M. Levitus, A. Pelliccia and A.A. Bouman, Test 1 analyser for determination of ESR. 2. Experimental evaluation and comparison with RBC aggregometry, Scand J Clin Lab Invest 70 (2010), 26-32.

[68] D. Justo, N. Mashav, Y. Arbel, M. Kinori, A. Steinvil, M. Swartzon, B. Molat, A. Halkin, A. Finkelstein, R. Heruti and S. Banai, Increased erythrocyte aggregation in men with coronary artery disease and erectile dysfunction, International Journal of Impotence Research 21 (2009), 192-197.

[69] H. Kiesewetter, H. Radtke, R. Schneider, K. Mussler, A. Scheffler and H. Schmid-Schonbein, The mini erythrocyte aggregometer: A new apparatus for the rapid quantification of the extent of erythrocyte aggregation, Biomed Tech (Berlin) 28 (1982), 209-213.

[70] S. Kim, P.K. Ong, O. Yalcin, M. Intaglietta and P.C. Johnson, The cell-free layer in microvascular blood flow, Biorheology 46 (2009), 181-189.

[71] L.A. Kirshenbaum, M. Asis, M.E. Astiz, D.C. Saha and E.C. Rackow, Influence of rheologic changes and plateletneutrophil interaction on cell filtration in sepsis, Am J Respir Crit Care Med 161 (2000), 1602-1607.

[72] B. Klitzman and B.R. Duling, Microvascular hematocrit and red cell flow in resting and contracting striated muscle, Am J Physiol 237 (1979), H481-H490.

[73] J. Koscielny, F. Jung, C. Mrowietz, H. Kiesewetter and R. Latza, Blood fluidity, fibrinogen, and cardiovascular risk factors of occlusive arterial disease: Results of the Aachen study, Clin Hemorheol Microcirc 31 ( 2004), 185-195.

[74] H.C. Kwaan, Role of plasma proteins in whole blood viscosity: A brief clinical review, Clin Hemorheol Microcirc 44 (2010), 167-176.

[75] C. Le Devehat, T. Khodabandehlou and M. Vimeux, Impaired hemorheological properties in diabetic patient with lower limb ischemia, Clin Hemorheol Microcirc 25 (2001), 43-48.

[76] N. Lebensohn, A. Re, L. Carrera, L. Barberena, M. D’Arrigo and P. Foresto, Serum sialic acid, cellular anionic charge and erythrocyte aggregation in diabetic and hypertensive patients, Medicina-Buenos Aires 69 (2009), 331-334.

[77] B.K. Lee, A. Durairaj, A. Mehra, R.B. Wenby, H.J. Meiselman and T. Alexy, Microcirculatory dysfunction in cardiac syndrome X: Role of abnormal blood rheology, Microcirculation 15 (2008), 451-459.

[78] B.K. Lee, A. Durairaj, A. Mehra, R.B. Wenby, H.J. Meiselman and T. Alexy, Hemorheological abnormalities in stable angina and acute coronary syndromes, Clin Hemorheol Microcirc 39 (2008), 43-51.

[79] W.S. Lee and T.Y. Kim, Measuring of ESR With TEST 1 Is More Useful Than the Westergren Method in Rheumatoid Arthritis, American Journal of Clinical Pathology 132 (2009), 805.

[80] M. Leschke, W. Motz, H. Blanke and Strauer, Blood rheology in hypertension and hypertensive heart disease, J Cardiovasc Pharmacol 10 (1987), S103-S110. 
[81] G.Y.H. Lip, Fibrinogen and cardiovascular disorders, Quart J Med 88 (1995), 155-165.

[82] H.H. Lipowsky, S. Kovalcheck and B.W. Zweifach, The distribution of blood rheological parameters in the microvasculature of cat mesentery, Circ Res 43 (1978), 738-749.

[83] J. Loscalzo, Nitric oxide insufficiency, platelet activation, and arterial thrombosis, Circulation Research 88 (2001), $756-762$.

[84] A. Luquita, L. Urli, M.J. Svetaz, A.M. Gennaro, R. Volpintesta, S. Palatnik and M. Rasia, Erythrocyte aggregation in rheumatoid arthritis: Cell and plasma factor's role, Clin Hemorheol Microcirc 41 (2009), 49-56.

[85] M. Mantskava, N. Momtselidze, N. Pargalava and G. Mchedlishvili, Hemorheological disorders in patients with type 1 or 2 diabetes mellitus and foot gangrene, Clin Hemorheol Microcirc 35 (2006), 307-310.

[86] H.J. Meiselman, Red blood cell role in RBC aggregation: 1963-1993 and beyond, Clin Hemorheol 13 (1993), 575-592.

[87] H.J. Meiselman, Hemorheologic alterations in hypertension: Chicken or egg? Clin Hemorheol Microcirc 21 (1999), 195-200.

[88] H.J. Meiselman, Red blood cell aggregation: 45 years being curious, Biorheology 46 (2009), 1-19.

[89] K. Michalska-Malecka and L. Slowinska-Lozynska, Aggregation and deformability of erythrocytes in primary open-angle glaucoma (POAG); the assesment of arterial hypertension, Clin Hemorheol Microcirc (2012). DOI 10.3233/CH-20121533.

[90] N. Momtselidze, M. Mantskava and G. Mchedlishvili, Hemorheological disorders during ischemic brain infarcts in patients with and without diabetes mellitus, Clin Hemorheol Microcirc 35 (2006), 261-264.

[91] G.B. Nash, T. Watts, C. Thornton and M. Barigou, Red cell aggregation as a factor influencing margination and adhesion of leukocytes and platelets, Clin Hemorheol Microcirc 39 (2008), 303-310.

[92] B. Neu and H.J. Meiselman, Depletion interactions in polymer solutions promote red blood cell adhesion to albumin-coated surfaces, Biochim Biophys Acta 1760 (2006), 1772-1779.

[93] B. Neu and H.J. Meiselman, The role of macromolecules in stabilization and de-stabilization of biofluids, in: G. Artmann and S. Chien, eds, Bioengineering in cell and tissue research, Springer, New York, 2008, pp. 387-408.

[94] B. Neu and H.J. Meiselman, Depletion-mediated red blood cell aggregation in polymer solutions, Biophys J 83 (2002), 2482-2490.

[95] B. Neu and H.J. Meiselman, Red blood cell aggregation, in: O.K. Baskurt, M.R. Hardeman, M.W. Rampling and H.J. Meiselman, eds, Handbook of Hemorheology and Hemodynamics, IOS Press, Amsterdam, Berlin, Oxford, Tokyo, Washington, DC, 2007, pp. 114-136.

[96] B. Neu, S.O. Sowemimo-Coker and H.J. Meiselman, Cell-cell affinity of senescent human erythrocytes, Biophys $J \mathbf{8 5}$ (2003), 75-84.

[97] B. Neu, R. Wenby and H.J. Meiselman, Effects of dextran molecular weight on red blood cell aggregation, Biophys J95 (2008), 3059-3065.

[98] F.J. Neumann, H.A. Katus, E. Hoberg, P. Roebruck, M. Braun, H.M. Haupt, H. Tillmanns and W. Kubler, Increased plasma viscosity and erythrocyte aggregation: Indicators of an unfavourable clinical outcome in patients with unstable angina pectoris, Br Heart J 66 (1991), 425-430.

[99] P.K. Ong, S.W.A.T. Jain, B.U.M.S. Namgung, Y.I. Woo and S.A.N.G. Kim, Cell-free layer formation in small arterioles at pathological levels of erythrocyte aggregation, Microcirculation 18 (2011), 541-551.

[100] M.J. Pearson and H.H. Lipowsky, Influence of erythrocyte aggregation on leukocyte margination in postcapillary venules of rat mesentery, Am J Physiol Heart Circ Physiol 279 (2000), H1460-H1471.

[101] A. Pirrelli, Arterial hypertension and hemorheology. What is the relationship? Clin Hemorheol Microcirc 21 (1999), $157-160$.

[102] M. Plebani, S. De Toni, M.C. Sanzari, D. Bernardi and E. Stockreiter, The TEST 1 automated system - A new method for measuring the erythrocyte sedimentation rate, American Journal of Clinical Pathology 110 (1998), 334-340.

[103] A.R. Pries, K. Ley, M. Claaben and P. Gaehtgens, Red cell distribution at microvascular bifurcations, Microvasc Res 38 (1989), 81-101.

[104] A.R. Pries, T.W. Secomb and P. Gaehtgens, Biophysical aspects of blood flow in the microvasculature, Cardiovasc Res 32 (1996), 654-667.

[105] R.R. Puniyani, V.S. Agashe, V. Annapurna and S.R. Daga, Haemorheological profile in cases of chronic infections, Clin Hemorheol 8 (1988), 595-602.

[106] M.W. Rampling, Haemorheology and the inflammatory process, Clin Hemorheol Microcirc 19 (1998), $129-132$.

[107] M.W. Rampling, Red cell aggregation and yield stress, in: G.D.O. Lowe, ed., Clinical blood rheology, CRC Press, Inc., Florida, 1988, pp. 45-64. 
[108] M.W. Rampling, H.J. Meiselman, B. Neu and O.K. Baskurt, Influence of cell-specific factors on red blood cell aggregation, Biorheology 41 (2004), 91-112.

[109] S.S. Raphael, Lynch's Medical Laboratory Technology, W.B. Saunders Co., Philadelphia, 1983.

[110] K.L. Resch, E. Ernst, A. Matrai, M. Buhl, P. Schlosser and H.F. Paulsen, Can Rheologic Variables be of Prognostic Relevance in Arteriosclerotic Diseases, Angiology 42 (1991), 963-970.

[111] R. Rotstein, R. Fusman, S. Berliner, D. Levartovsky, O. Rogowsky, S. Cohen, E. Shabtai, I. Shapira, D. Avitzour, N. Arber and D. Zeltser, The feasibility of estimating the erythrocyte sedimentation rate within a few minutes by using a simple slide test, Clinical and Laboratory Haematology 23 (2001), 21-25.

[112] H. Schmid-Schonbein, Fluid dynamics and hemorheology in vivo: The interactions of hemodynamic parameters and hemorheological "properties" in determining the flow behavior of blood in microvascular networks, in: G.D.O. Lowe, ed., Clinical blood rheology, CRC Press, Florida, 1988, pp. 129-219.

[113] S.L. Schrier, Pathophysiology of thalassemia, Curr Opin Hematol 9 (2002), 123-126.

[114] S. Shin, M.S. Park, Y.H. Ku and J.S. Suh, Shear-dependent aggregation characteristics of red blood cells in a pressuredriven microfluidic channel, Clin Hemorheol Microcirc 34 (2006), 353-361.

[115] S. Shin, Y. Yang and J.S. Suh, Measurement of erythrocyte aggregation in a microchip-based stirring system by light transmission, Clin Hemorheol Microcirc 41 (2009), 197-207.

[116] S. Shin, Y. Yang and J.S. Suh, Measurement of erythrocyte aggregation in a microchip-based stirring-system by analysis of light transmission and backscattering, Biorheology 45 (2008), 71-72.

[117] E. Sola, A. Vaya, M. Simo, A. Hernandez-Mijares, C. Morillas, F. Espana, A. Estelles and D. Corella, Fibrinogen, plasma viscosity and blood viscosity in obesity. Relationship with insulin resistance, Clin Hemorheol Microcirc 37 (2007), 309-318.

[118] M.I. Spengler, M.J. Svetaz, M.B. Leroux, S.M. Bertoluzzo, P. Carrara, F. Van Isseldyk, D. Petrelli, F.M. Parente and P. Bosch, Erythrocyte aggregation in patients with systemic lupus erythematosus, Clin Hemorheol Microcirc 47 (2011), 279-285.

[119] N. Tanahashi, M. Tomita, M. Kobari, H. Takeda, M. Yokoyama, M. Takao and Y. Fukuuchi, Platelet activation and erythrocyte aggregation rate in patients with cerebral infarction, Clinical Hemorheology 16 (1996), 497-505.

[120] I.A. Tikhomirova, A.O. Oslyakova and S.G. Mikhailova, Microcirculation and blood rheology in patients with cerebrovascular disorders, Clin Hemorheol Microcirc 49 (2011), 295-395.

[121] W. Tillmann, E. Friedrichs, J. Germs and A. Conrad, Increased erythrocyte aggregation in infections - influence of acute phase proteins, Onkologie 6 (1983), 246-247.

[122] S. Toker, O. Rogowski, S. Melamed, A. Shirom, I. Shapira, S. Berliner and D. Zeltser, Association of components of the metabolic syndrome with the appearance of aggregated red blood cells in the peripheral blood. An unfavorable hemorheological finding, Diabetes-Metabolism Research and Reviews 21 (2005), 197-202.

[123] A. Vaya, A. Hernandez-Mijares, E. Bonet, R. Sendra, E. Sola, R. Perez, D. Corella and B. Laiz, Association between hemorheological alterations and metabolic syndrome, Clin Hemorheol Microcirc 49 (2011), 493-503.

[124] A. Vaya, A. Hernandez-Mijares, M. Suescun, E. Sola, R. Camara, M. Romagnoli, D. Bautista and B. Laiz, Metabolic alterations in morbid obesity. Influence on the haemorheological profile, Clin Hemorheol Microcirc 48 (2011), 247-255.

[125] A. Vaya, M. Martinez, J. Garcia and J. Aznar, The hemorheological profile in mild essential hypertension, Thromb Res 66 (1992), 223-229.

[126] A. Vaya, J. Calvo, C. Alcala, L. Mico, J. Todoli and J.M. Ricart, Rheological alterations and thrombotic events in patients with systemic lupus erythematosus, Clin Hemorheol Microcirc 51 (2012), 51-58.

[127] J. Vekasi, Zs. Marton, G. Kesmarky, A. Cser, R. Russai and B. Horvath, Hemorheological alterations in patients with diabetic retinopathy, Clin Hemorheol Microcirc 24 (2001), 59-64.

[128] X. Waltz, M. Hedreville, S. Sinnapah, Y. Lamarre, V. Soter, N. Lemonne, M. Etienne-Julan, E. Beltan, T. Chalabi, R. Chout, O. Hue, D. Mougenel, M.-D. Hardy-Dessources and P. Connes, Delayed beneficial effect of acute exercise on red blood cell aggregate strength in patients with sickle cell anemia, Clin Hemorheol Microcirc (2012), DOI 10.3233/CH-2012-1540.

[129] O. Yalcin, F. Aydin, P. Ulker, M. Uyuklu, F. Gungor, J.K. Armstrong, H.J. Meiselman and O.K. Baskurt, Effects of red blood cell aggregation on myocardial hematocrit gradient using two approaches to increase aggregation, American Journal of Physiology-Heart and Circulatory Physiology 290 (2006), H765-H771.

[130] O. Yalcin, P. Ulker, U. Yavuzer, H.J. Meiselman and O.K. Baskurt, Nitric oxide generation of endothelial cells exposed to shear stress in glass tubes perfused with red blood cell suspensions: Role of aggregation, Am J Physiol Heart Circ Physiol 294 (2008), H2098-H2105. 
[131] W.G. Zijlstra, Syllectometry, a new method for studying rouleaux formation of red blood cells, Acta Phys Pharm Neerl 7 (1958), 153-154.

[132] D. Zilberman-Kravits, I. Harman-Boehm, T. Shuster and N. Meyerstein, Increased red cell aggregation is correlated with HbA1C and lipid levels in type 1 but not type 2 diabetes, Clin Hemorheol Microcirc 35 (2006), 463-471.

[133] E. Zorio, J. Murado, D. Arizo, J. Rueda, D. Corella, M. Simo and A. Vaya, Haemorheological parameters in young patients with acute myocardial infarction, Clin Hemorheol Microcirc 39 (2008), 33-41. 
Copyright of Clinical Hemorheology \& Microcirculation is the property of IOS Press and its content may not be copied or emailed to multiple sites or posted to a listserv without the copyright holder's express written permission. However, users may print, download, or email articles for individual use. 